\title{
SEISMIC IMAGING OF HIGH SLOPE STRUCTURES USING ONE-WAY WAVE EQUATION MIGRATION TECHNIQUES
}

\author{
Adeilton Rigaud Lucas Santos ${ }^{1}$, Reynam da Cruz Pestana² and Gary Corey Aldunate ${ }^{2}$
}

\begin{abstract}
The two-way wave equation deal with the wavefield in all of its forms, including multiples, refractions and internal reflections in more than one layer. Disregarding the downgoing wavefield, that is, considering only the propagation of the upgoing wavefield, starts using the one-way wave equation and some of these events are not considered. Thus, in areas of simple geology, the solution of the one-way wave equation is a good approximation. However, if the geology is complex, with abrupt lateral velocity variations and sub-vertical interfaces, such as in the presence of salt domes, methods of migration employing the one-way wave equation fail in imaging this kind of structures. In this paper, we present a way to overcome this limitation, by propagating the downgoing wavefield in following step upgoing wavefield. From these two extrapolated wavefields we apply four different imaging conditions, generating four intermediate sections, and the migrated section is formed from the weighted sum between the previous intermediate sections. This migration method was tested in two geological models (vertical fault and in a representative section of the Santos basin) and was able to reconstruct the complex structures existing in the models.
\end{abstract}

Keywords: seismic migration, Fourier domain, sub-vertical reflectors.

RESUMO. A equação completa da onda trata da propagação do campo de ondas em todas as suas formas, incluindo múltiplas, refrações e reflexões internas em mais de uma camada. Ao desprezar o campo de ondas descendente, ou seja, ao considerar a propagação apenas do campo ascendente, passa-se a empregar a equação unidirecional da onda e parte destes eventos não são considerados. Desta forma, em áreas de geologia simples, a solução da equação unidirecional é uma boa aproximação, entretanto, caso a geologia seja complexa, apresentando variações laterais bruscas de velocidade e interfaces subverticais, tal como na presença de domos salinos, os métodos de migração que empregam a equação unidirecional falham no imageamento das estruturas. Neste trabalho, apresenta-se uma forma de transpor esta limitação, através da propagação do campo de ondas descendente, numa etapa seguinte à do campo ascendente. A partir desses dois campos extrapolados, aplicam-se quatro condições de imagem distintas, gerando quatro seções intermediárias, e a seção migrada será formada a partir da soma ponderada entre as seções anteriores. Este método de migração foi testado em dois modelos geológicos (falha vertical e seção tipo da bacia de Santos) e mostrou-se capaz de reconstruir as estruturas mais complexas existentes nos modelos.

Palavras-chave: migração sísmica, domínio de Fourier, refletores subverticais.

\footnotetext{
1 PETROBRAS, Unidade de Operações de Exploração e Produção do Espírito Santo, UO-ES/EXP/PS, EDIVIT, Bloco 4/Pilotis 2, Av. Nossa Senhora da Penha, 1688, Barro Vermelho, 29057-550 Vitória, ES, Brazil. Phone: +55(27) 3295-1810; Fax: +55(27) 3295-4705 - E-mail: aderigaud@petrobras.com.br

2Universidade Federal da Bahia, Instituto de Geociências, CPGG/UFBA, Centro de Pesquisa em Geofísica e Geologia, sala 312-C, Campus Universitário de Ondina, 40170-115 Salvador, BA, Brazil. Phone: +55(71) 3283-8512; Fax: +55(71) 3283-8501 - E-mails: reynam@cpgg.ufba.br; gcap@cpgg.ufba.br
} 


\section{INTRODUCTION}

The spectral techniques of migration are well known to have a wavefield extrapolation performed in the Fourier domain (frequency and wave number). Seismic data are recorded in the space-time domain $(x-t)$ and to be converted to the Fourier domain $(k-\omega)$ are undergoing transformed namesake. The algorithms Stolt (Stolt, 1978), Phase Shift (Gazdag, 1978), Split Step (Freire, 1988), Phase Shift Plus Interpolation - PSPI (Gazdag \& Sguazzero, 1984) and Fourier Finite Difference - FFD (Ristow \& Ruhl, 1994) are in this category of migration methods.

These migration methods are relatively fast and perform the wavefield extrapolation based on properties of the translation in time and the derivative of the Fourier transform. However, a major limitation of these algorithms is the use of the one-way wave equation, ignoring the downgoing wavefield, which prevents the imaging of high slope structures, whose reflections have trajectories with reflection on more than one interface.

In spectral techniques, the wavefield recorded at the surface is converted to the Fourier domain and extrapolated using the translation in time property, followed by the application of the imaging condition to build the migrated image. To get to the extrapolation operators, we start from the wave equation, carried out the time $(t \leftrightarrow \omega)$ and space $\left(x \leftrightarrow k_{x}\right)$ Fourier transform and considering the medium with variable velocity only in $z$, we have the following equation:

$$
\frac{\partial^{2} \check{\check{P}}}{\partial z^{2}}=-k_{z}^{2} \check{\check{P}}
$$

where $P$ is the wavefield, $k_{z}$ is the wavenumber in the $z$ direction and $\check{P}$ is the wavefield in the Fourier domain. This equation can be rearranged to decouple the upgoing and downgoing wavefields:

$$
\underbrace{\left(\frac{\partial}{\partial z}-i k_{z}\right)}_{\text {upgoing }} \underbrace{\left(\frac{\partial}{\partial z}+i k_{z}\right)}_{\text {downgoing }} \check{\check{P}}=0
$$

Using the upgoing solution as a approximation for the complete wavefield, we have a first-order partial differential equation, which recursive solution for extrapolate the wavefield is:

$$
\check{\check{P}}(z+\Delta z)=e^{i k_{z} \Delta z} \check{\check{P}}(z)
$$

which is the basis for spectral techniques migration operators, where $k_{z}$ is determined by the dispersion relation:

$$
k_{z}= \pm \sqrt{\frac{\omega^{2}}{c_{0}^{2}(z)}-k_{x}^{2}}
$$

where $\omega$ is the temporal frequency, $c$ is the velocity and $k_{x}$ is the wavenumber in the $x$ direction.

The recursive solution presented above is the operator for phase shift migration that is useful for a vertical variable velocity model (Gazdag, 1978). Split Step (Freire, 1988), PSPI (Gazdag \& Sguazzero, 1984) and FFD (Ristow \& Ruhl, 1994) operators were developed to add the capability to handle lateral velocity variation during migration in the Fourier domain.

This study compared the results employing the migration methods Split Step and PSPI with an alternative algorithm, here called Up-Down, which employs a mixed Split Step and PSPI techniques and considers both the upgoing and downgoing wavefields (Biondi, 2006) and (Aldunate \& Pestana, 2006). Moreover, the response of the reverse time migration (RTM) is presented in order to compare the Up-Down algorithm with that two-way wave equation migration. These methods were employed in synthetic data generated from two distinct geological models, the first representative of a vertical fault and the second in a geologic section of the Santos basin.

\section{UP-DOWN ALGORITHM}

Despite the spectral techniques allow the migration of seismic data recorded in areas with lateral varying velocity, the correct imaging of high-dip structures (sub-vertical) is not possible, mainly due to the contempt of the downgoing wavefield during migration. To break through this limitation, (Zhang et al., 2006) proposed the extrapolation of the wavefield in two steps, first the upgoing and then the downgoing wavefield, allowing imaging of structures associated with duplex waves (those ones who has more than one reflection during propagation).

This algorithm, here called Up-Down, was implemented with the operator Split Step Phase Shift Plus Interpolation - SS-PSPI (Aldunate \& Pestana, 2006). It extrapolates the wavefield using the Split Step algorithm for several reference velocities and then interpolates the results similar to the PSPI method.

The operator of the Up-Down algorithm is obtained from Eq. (2), but instead of considering only the upgoing wavefield, performs a second extrapolation step for the downgoing wavefield. The results are combined to generate migrated final section:

$$
\left(\frac{\partial}{\partial z}-i k_{z}\right) \check{\check{U}}=0 \quad\left(\frac{\partial}{\partial z}+i k_{z}\right) \check{\check{D}}=0
$$

where $D$ and $U$ corresponds, respectively, to the downgoing and upgoing wavefields. After mathematical development as similar as mentioned above, we reach the extrapolation operators of the 
upgoing and downgoing wavefields:

$$
\begin{aligned}
& \check{\check{U}}(z+\Delta z)=e^{i k_{z} \Delta z} \check{\breve{U}}(z) \\
& \check{\check{D}}(z+\Delta z)=e^{-i k_{z} \Delta z} \check{\check{D}}(z)
\end{aligned}
$$

where $k_{z}$, in order to consider lateral variation in the velocity (Split Step) is defined by the following relationship:

$$
k_{z}=\sqrt{\frac{\omega^{2}}{c_{0}^{2}}-k_{x}^{2}}+\omega\left(\frac{1}{c(x, z)}-\frac{1}{c_{0}(z)}\right)
$$

The Up-Down algorithm is implemented in pre-stack seismic data in common shot domain, so that the operators defined in Eq. (6) are used to propagate the source wavefield and depropagate the seismic data from receiver, both the downgoing and the upgoing wavefield. At the end of this process, there will be four sets of data to be used to form intermediate migrated seismic sections $\left(S_{D}-R_{D}, S_{D}-R_{U}, S_{U}-R_{D}, S_{U}-R_{U}\right) . S$ and $R$ are the source and receiver wavefields, respectively, and the index ${ }_{U}$ and ${ }_{D}$ represents the upgoing and downgoing wavefields, in that order. The imaging condition used in this algorithm is the cross-correlation of receiver and source wavefields, as showed below:

$$
\begin{aligned}
& P_{D D}(x, z)=\sum_{\omega} R_{D}(x, z, \omega) \star S_{D}^{*}(x, z, \omega) \\
& P_{U D}(x, z)=\sum_{\omega} R_{U}(x, z, \omega) \star S_{D}^{*}(x, z, \omega) \\
& P_{D U}(x, z)=\sum_{\omega} R_{D}(x, z, \omega) \star S_{U}^{*}(x, z, \omega) \\
& P_{U U}(x, z)=\sum_{\omega} R_{U}(x, z, \omega) \star S_{U}^{*}(x, z, \omega)
\end{aligned}
$$

where $P$ is the intermediate wavefield formed by crosscorrelation (denoted by $\star$ ) between the wavefields indicated in the index. The intermediate migrated sections are weighted summed in order to generate the final migrated section of the Up-Down method. The weights will vary according to the migrated data in order to normalize the amplitude values obtained at each intermediate section. The weight can be zero and hence that section will not contribute to the construction of the final migration:

$$
\begin{aligned}
P(x, z)= & \Gamma_{D D} P_{D D}+\Gamma_{U D} P_{U D} \\
& +\Gamma_{D U} P_{D U}+\Gamma_{U U} P_{U U}
\end{aligned}
$$

where $\Gamma$ are the weights for each intermediate section and $P(x, z)$ is the final migrated seismic section.

\section{GEOLOGICAL MODELS}

The first geological model used was relatively simple, presenting a vertical structure. The model comprises two superimposed horizontal layers of different velocities, with a 90 degrees discontinuity, representing a vertical fault with $700 \mathrm{~m}$ of displacement (Fig. 1). The synthetic seismic data of this model was obtained from finite differences modeling using the program sufdmod2_pm/ in Seismic Unix (SU), which works with the acoustic wave equation using second order approximations and Perfectly Matched Layer (PML) absorbing boundary condition (Berenger, 1994). The modeling took place in a uniform grid of $5 \mathrm{~m}(\Delta x=\Delta z=5 \mathrm{~m})$ and with a $25 \mathrm{~Hz}$ Ricker wavelet. These parameters were good enough to avoid numerical dispersion and instability in finite differences modeling.

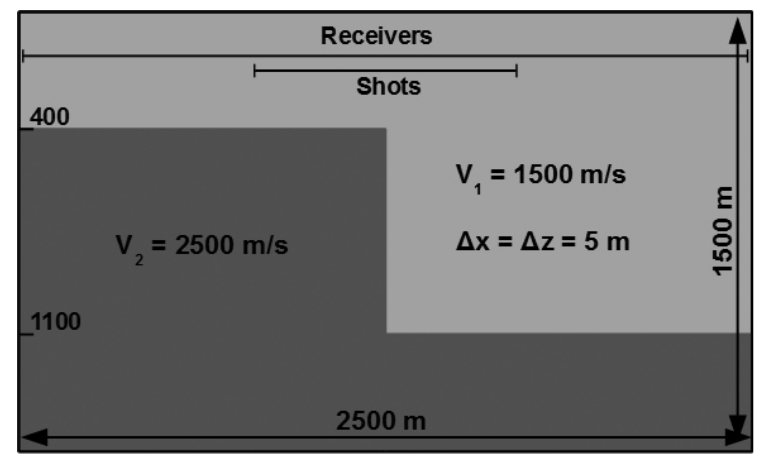

Figure 1 - Geological model used in this study, representing a vertical fault with $700 \mathrm{~m}$ displacement.

The second model used in this work is representative of a geologic section of the Santos basin (Fig. 2) and the synthetic data were generated with viscoelastic modeling held at the Leopoldo A. Miguez de Mello Research \& Development Center (CENPES/Petrobras). The velocity field was obtained by lateral extrapolation of the elastic properties from one well, combined with the mapped horizons in seismic data pre-existing (Martins \& Santos, 2010). The synthetic data was obtained through modeling of 381 shots spaced 50 m apart, with 500 receivers every $10 \mathrm{~m}$, in a regular grid of $2 \mathrm{~m}(\Delta x=\Delta z=2 \mathrm{~m})$ and with a $25 \mathrm{~Hz}$ Ricker wavelet. The modeling was performed ignoring multiples and absorption edge in the four physical limits of the model.

\section{OBTAINED RESULTS}

In the vertical fault model, the Split Step and PSPI methods failed to image the vertical interface, but the Up-Down algorithm was able to reconstruct the vertical fault, using the information obtained from the propagation of the upgoing wavefield (Fig. 3). The Up-Down result is very similar to the one of the RTM. 


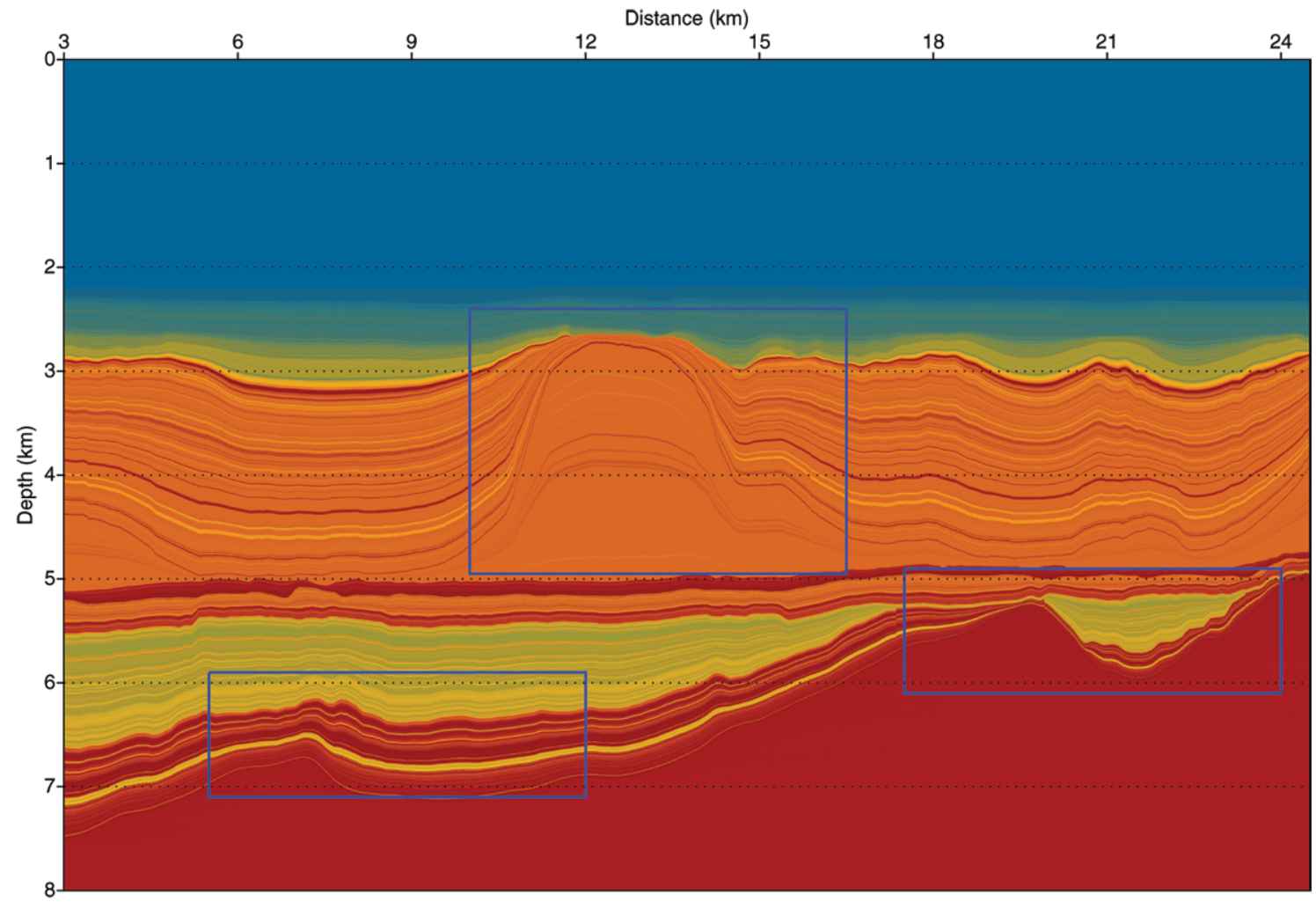

Figure 2 - Geological model used in this study, representing a geological section of the Santos basin. The blue rectangles demarcate the regions that will be detailed in the migrated data.

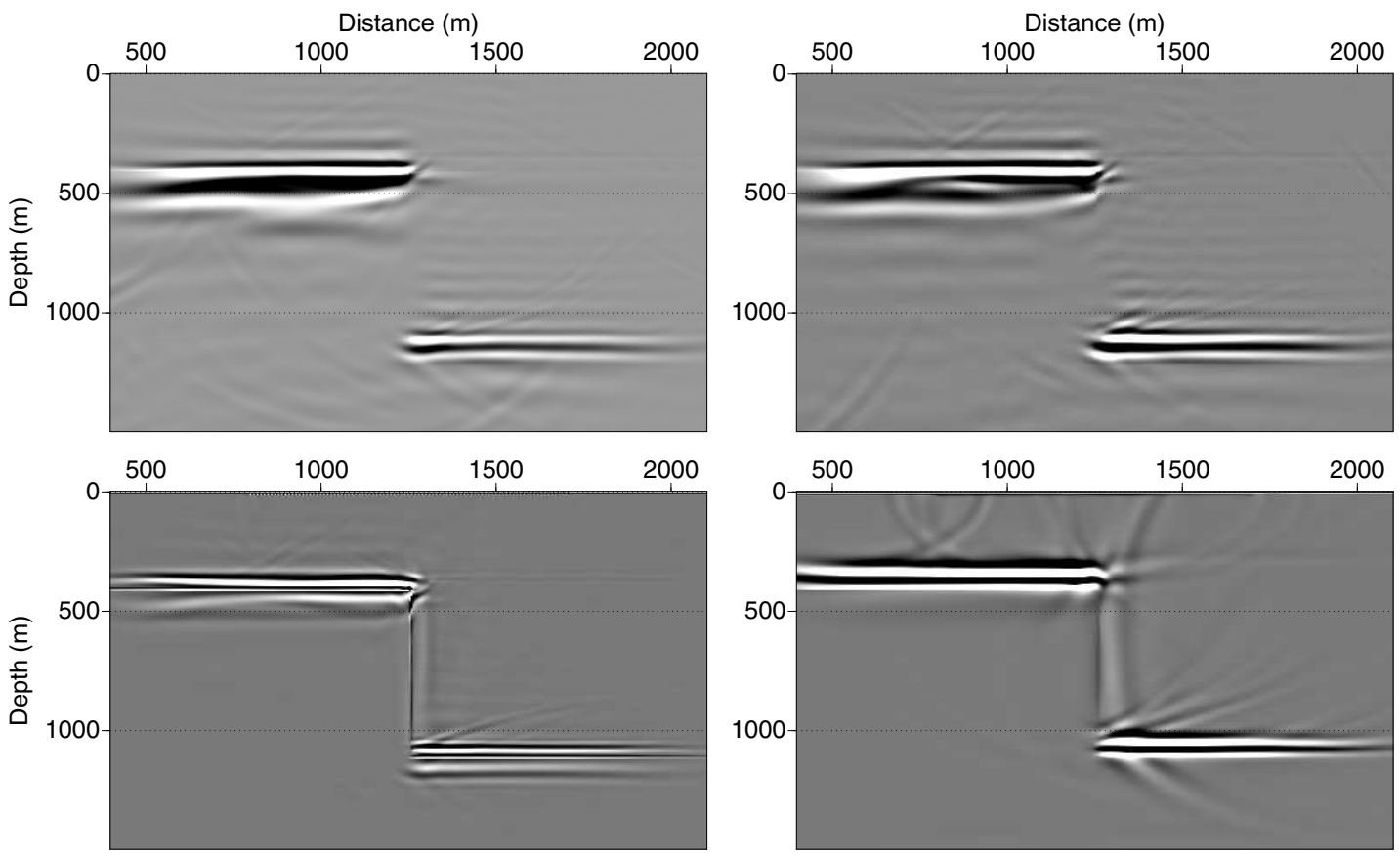

Figure 3 - Result of the migration from vertical fault model data, with the algorithms Split Step (upper left), PSPI (upper rigth), Up-Down (bottom left) and RTM (bottom rigth). Note that only the two latter were able to reconstruct the vertical structure of the model. 
Similarly, in the Santos basin model, the Up-Down algorithm also presented better response than the others one-way wave equation methods, as we can see in the dipping structures in the top of the dome located in the center of the section. Moreover, this technique was able to resolve thin layers that are not differentiated with methods Split Step and PSPI, particularly at greater depths (Figs. 4 to 6). In addition, the Up-Down algorithm has a result as good as that one showed by the RTM (Fig. 7).
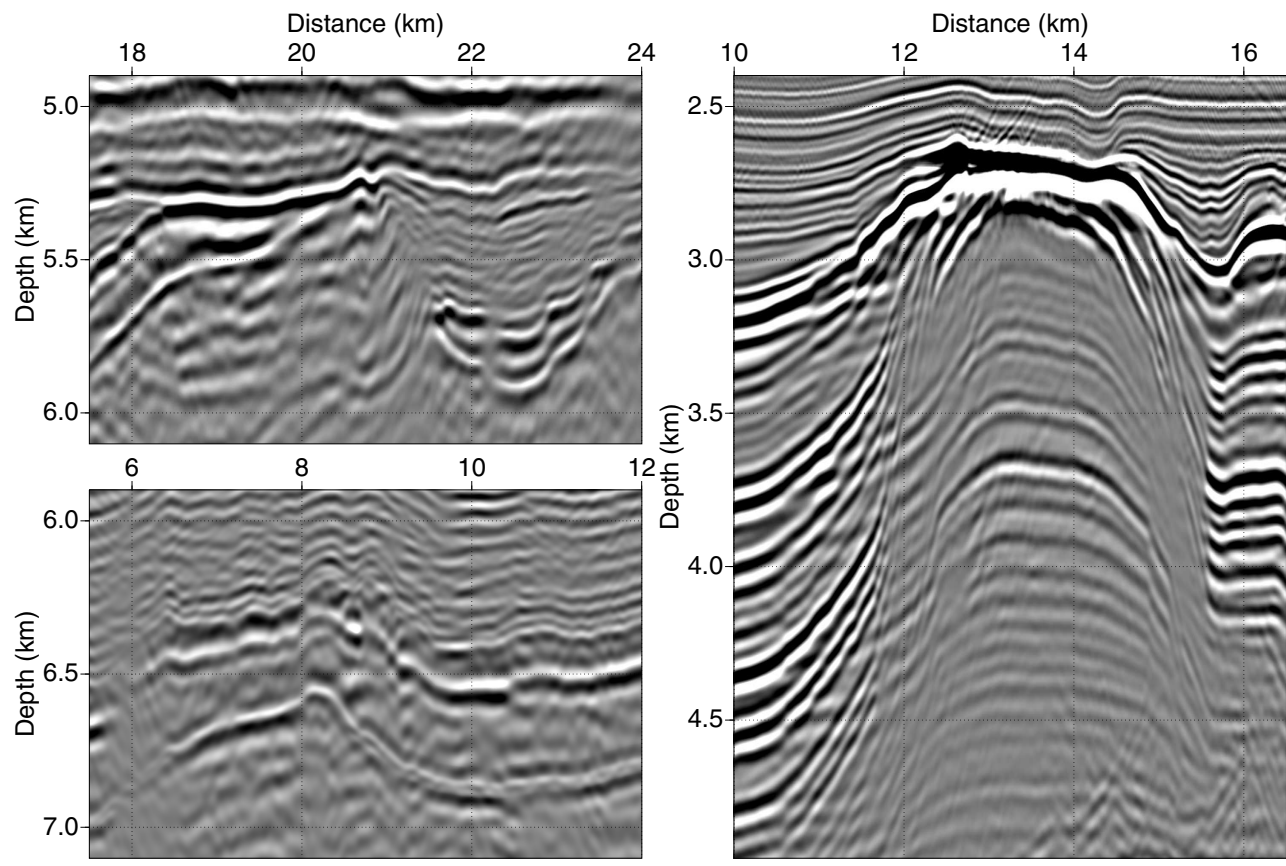

Figure 4 - Result of the migration from Santos basin synthetic data using Split Step algorithm.
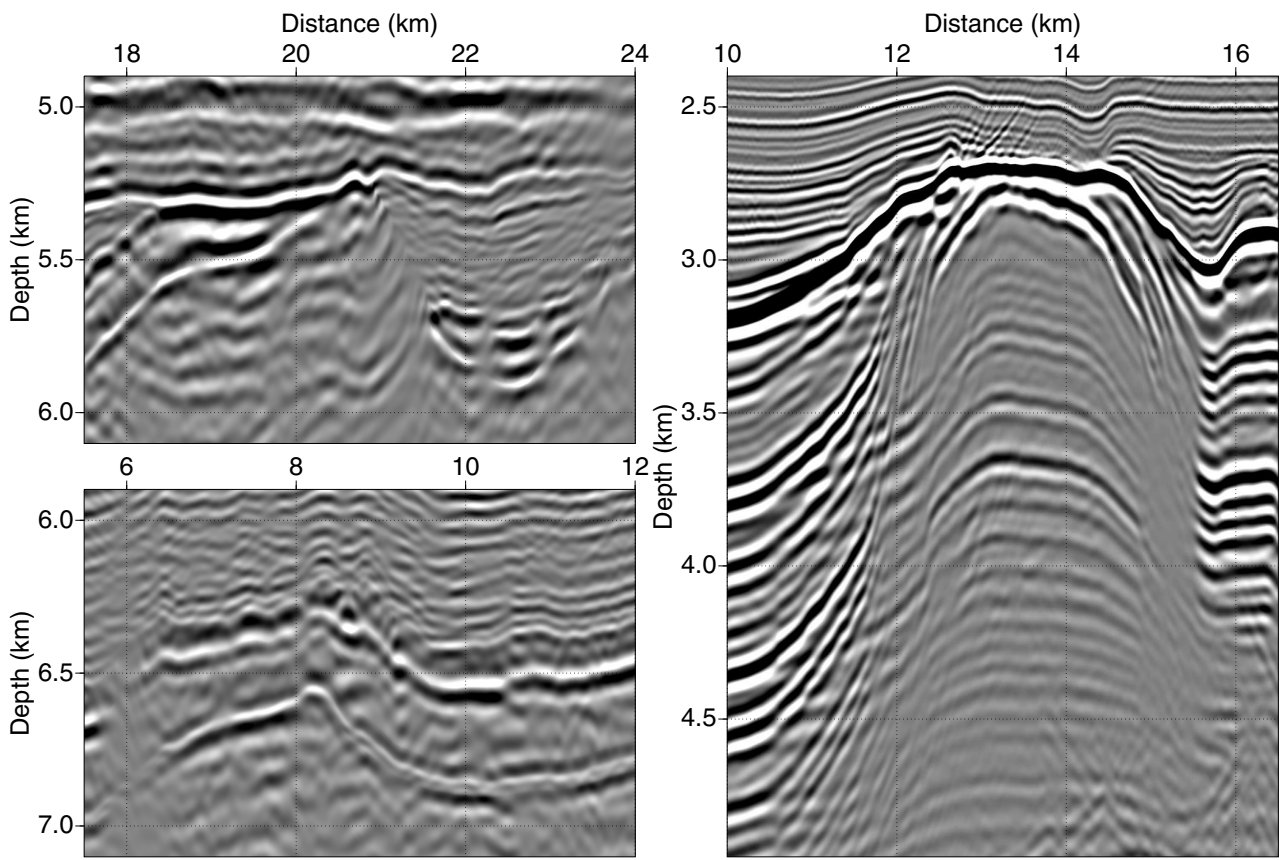

Figure $\mathbf{5}$ - Result of the migration from Santos basin synthetic data using PSPI algorithm. 


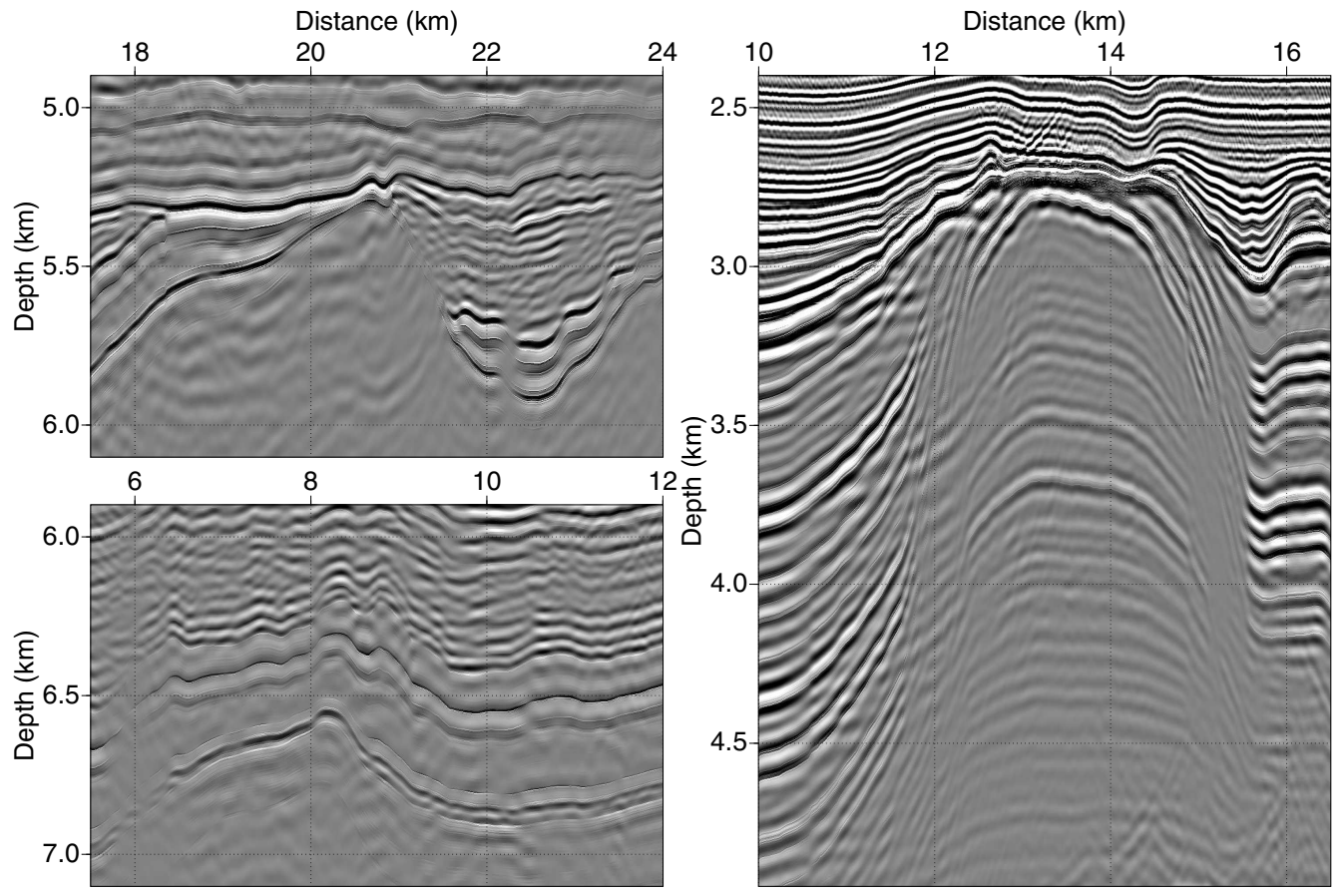

Figure $\mathbf{6}$ - Result of the migration from Santos basin synthetic data using Up-Down algorithm.
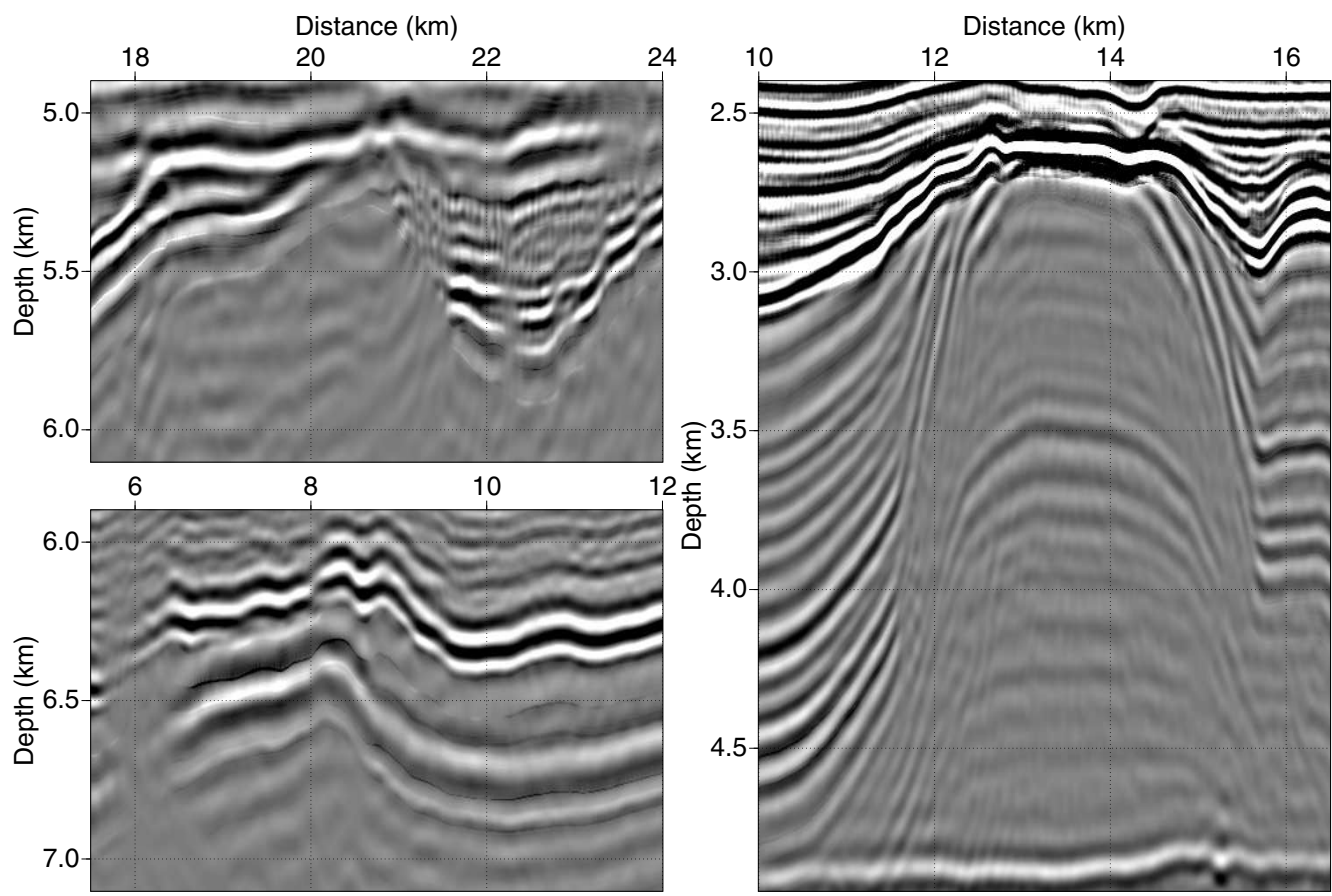

Figure 7 - Result of the migration from Santos basin synthetic data using RTM algorithm. 

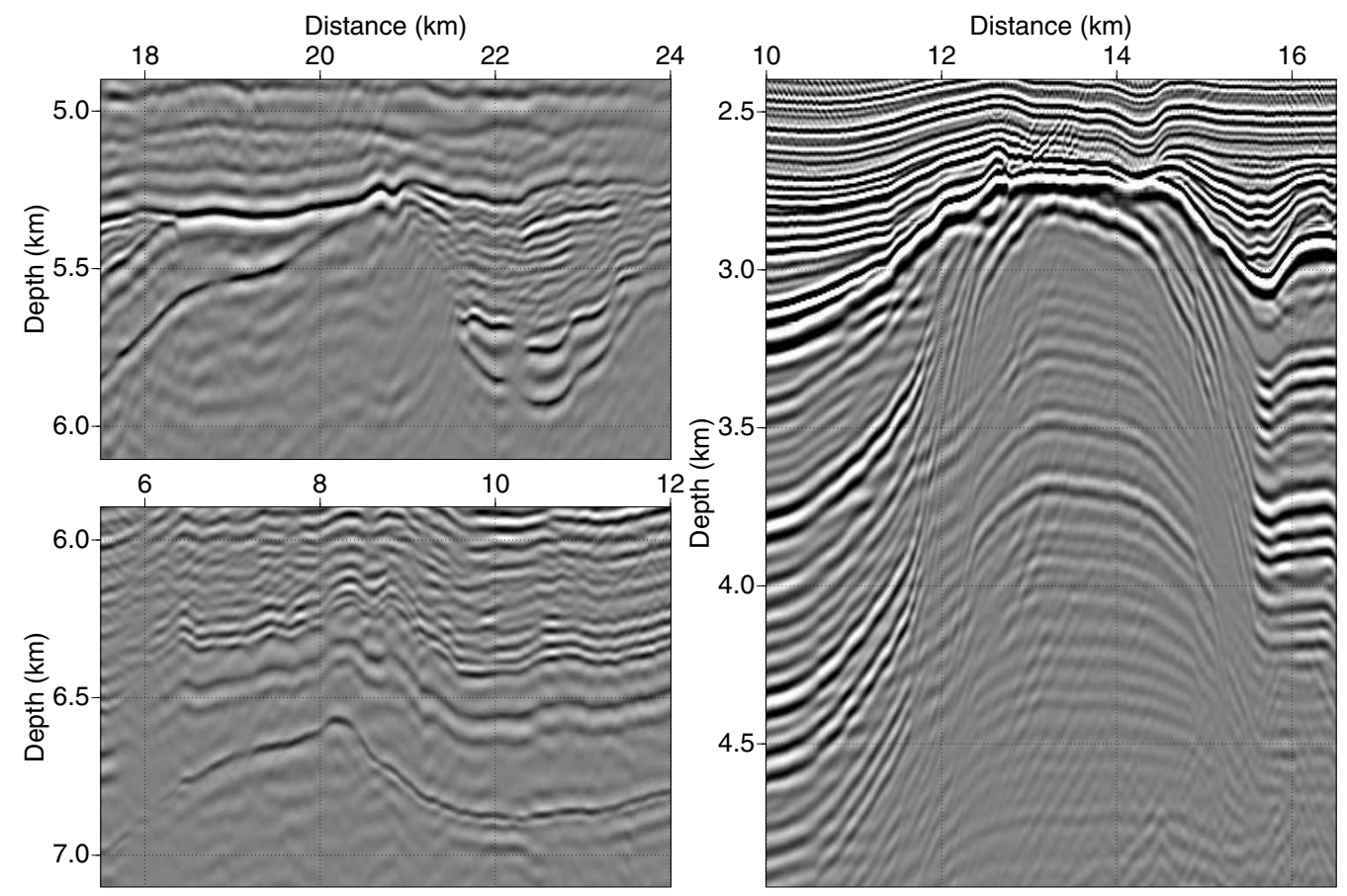

Figure 8 - Result of the migration from Santos basin synthetic data using Up-Down algorithm, using a smoothed velocity field.

The imaging condition used in these algorithms is the crosscorrelation between the wavefields of the source and receivers. Due to the cross-correlation of undesirable events, the data migrated with the Up-Down and RTM algorithms are contaminated with low-frequency artifacts that are eliminated applying a Laplacian filter. The Laplacian filter was applied ignoring the diagonal elements from the mask, performing the following operation in the data:

$$
\begin{gathered}
\nabla^{2} f(x, y)=[f(x+1, y)+f(x-1, y) \\
+f(x, y+1)+f(x, y-1)]-4 f(x, y)
\end{gathered}
$$

Despite of the elimination of the noise, the Laplacian filter also removes part of the signal, changes the phase and amplifies high frequency noise after its application (Guitton et al., 2007). The velocity field smoothing reduces the amount of backscattered waves and in consequence greatly reduces the presence of this last noise (Fig. 8).

\section{CONCLUSIONS}

The extrapolation of the wavefield in the frequency domain is computationally efficient and numerically stable, which makes attractive the use of spectral techniques in the migration of seismic data. However, disregarding the downgoing wavefield, a major limitation in imaging high dipping structures is imposed to these algorithms. These structures are illuminated by waves that have more than one reflection and reconstruction of these interfaces in the migrated section needs to employ also the downgoing wavefield, as performed by the Up-Down algorithm or the two-way wave equation method (RTM).

The results obtained with the migration of data from the vertical fault model clearly demonstrates the limitations of conventional spectral techniques imaging and the capability of the UpDown algorithm. The Santos basin model also showed better results when their data has been migrated with the Up-Down algorithm, which was able to imaging structures associated with the walls of the dome structure at the center of the section. In addition, the Up-Down algorithm also showed a superior ability to resolve thin layers from the model, specially in the deeper portions.

The imaging condition of the Up-Down algorithm generates low-frequency artifacts, that are attenuated by using a Laplacian filter, but this also removes part of the signal, changes the phase and amplifies high frequency noise. Smoothing the velocity field reduces the effect of the latter noise, however the characteristics of the wavefield extrapolation can be affected with this softening and consequently the result of migration may be affected.

The comparison between Up-Down and RTM reveal data with similar structural imaging, however should be considered that 
using the same processing capability, the Up-Down is more than six time faster than RTM, even using a sparse grid (Table 1). Thus, the Up-Down should be considered as a optional algorithm to be used when hardware is a issue in seismic migration of data with high slope structures (complex geology).

Table 1 - Migration time of the Santos basin data for the algorithms used in this work.

\begin{tabular}{|c|c|c|c|}
\hline \multicolumn{4}{|c|}{ Migration time } \\
\hline Algorithm & Time (h:m:s) & $\Delta \mathrm{x}(\mathrm{m})$ & $\Delta \mathrm{z}(\mathrm{m})$ \\
\hline Split Step & $01: 11: 57$ & 5 & 2 \\
PSPI & $03: 38: 26$ & 5 & 2 \\
Up-Down & $07: 21: 50$ & 5 & 2 \\
RTM & $45: 16: 35$ & 10 & 4 \\
\hline
\end{tabular}

\section{ACKNOWLEDGEMENTS}

The authors would like to thanks Petrobras for the master's degree research opportunity and the Center for Research in Geophysics and Geology, Universidade Federal da Bahia (CPGG/UFBA) by the structure and facilities available for the same.

\section{REFERENCES}

ALDUNATE GC \& PESTANA RC. 2006. Método híbrido de migração pré-empilhamento em profundidade no domínio da frequência em duas etapas com interpolação. Brazilian Journal of Geophysics, 24(1): 91-102.
BERENGER J. 1994. A perfectly matched layer for the absorption of electromagnetic waves. Journal of Computational Physics, 114(2): 185-200.

BIONDI BL. 2006. 3-D seismic imaging. Investigation on Geophysics, no. 14. Society of Exploration Geophysicist.

FREIRE RML. 1988. Migração por mudança de fase em duas etapas. Doctorate Thesis on Physics, PPPG/UFBA, Salvador, Bahia, Brazil, $164 \mathrm{pp}$.

GAZDAG J. 1978. Wave equation migration with the phase shift method. Geophysics, 43: 1342-1351.

GAZDAG J \& SGUAZZERO P. 1984. Migration of seismic data by Phase Shift Plus Interpolation. Geophysics, 49: 124-131.

GUITTON A, KAELIN B \& BIONDI B. 2007. Least-squares attenuation of reverse-time-migration artifacts. Geophysics, 72: S19-S23.

MARTINS EO \& SANTOS LA. 2010. Análise de velocidade em tempo de dados resultantes de modelagem sísmica em modelo sintético do présal. Relatório técnico parcial, CENPES - Centro de Pesquisas e Desenvolvimento Leopoldo A. Miguez de Mello, Junho.

RISTOW D \& RUHL T. 1994. Fourier finite-difference migration. Geophysics, 59: 1882-1893.

STOLT RH. 1978. Migration by Fourier transform. Geophysics, 43: 23-48.

ZHANG Y, XU S \& ZHANG G. 2006. Imaging complex salt bodies with turning-wave one-way wave equation. In: SEG Annual Meeting, 76., New Orleans, Louisiana, USA, pp. 2323-2327.

\section{NOTES ABOUT THE AUTHORS}

Adeilton Rigaud Lucas Santos received a B.Sc. in Geology from UFRN (2002) and M.Sc. in Geophysics from UFBA (2013). Has been working in Petrobras since 2003, on the Espírito Santo Operational Unit (UO-ES). Areas of interest include seismic modeling for acquisition, seismic data processing and seismic imaging.

Reynam da Cruz Pestana received a B.Sc. in Physics (1984) and Ph.D. in Geophysics from UFBA (1988). Researcher and professor at Center for Research in Geophysics and Geology (CPGG/UFBA), working in applied geophysics for oil and gas industry. Areas of interest include reverse time migration, plane waves migration, seismic imaging and velocity analysis. Awarded in 2013 the Nero Passos prize (SBGf) as Researcher and Educator in Geophysics.

Gary Corey Aldunate received a B.Sc. in Physics from UATF-Bolívia (1997) and M.Sc. in Geophysics from UFBA (2002), where currently is a Ph.D. student in the Center for Research in Geophysics and Geology (CPGG/UFBA). Main areas of interest are seismic modeling, seismic data processing and seismic imaging. 